\title{
Global invasion history of the emerging plant pathogen Phytophthora multivora
}

\author{
Tetyana Tsykun ${ }^{1,2,3^{*}}$, Simone Prospero ${ }^{3}$, Corine N. Schoebel ${ }^{3}$, Alexander Rea ${ }^{4,5}$ and Treena I. Burgess 5,6
}

\begin{abstract}
Background: global trade in living plants and plant material has significantly increased the geographic distribution of many plant pathogens. As a consequence, several pathogens have been first found and described in their introduced range where they may cause severe damage on naive host species. Knowing the center of origin and the pathways of spread of a pathogen is of importance for several reasons, including identifying natural enemies and reducing further spread. Several Phytophthora species are well-known invasive pathogens of natural ecosystems, including Phytophthora multivora. Following the description of P. multivora from dying native vegetation in Australia in 2009, the species was subsequently found to be common in South Africa where it does not cause any remarkable disease. There are now reports of P. multivora from many other countries worldwide, but not as a commonly encountered species in natural environments.

Results: a global collection of 335 isolates from North America, Europe, Africa, Australia, the Canary Islands, and New Zealand was used to unravel the worldwide invasion history of P. multivora, using 10 microsatellite markers for all isolates and sequence data from five loci from 94 representative isolates. Our population genetic analysis revealed an extremely low heterozygosity, significant non-random association of loci and substantial genotypic diversity suggesting the spread of $P$. multivora readily by both asexual and sexual propagules. The P. multivora populations in South Africa, Australia, and New Zealand show the most complex genetic structure, are well established and evolutionary older than those in Europe, North America and the Canary Islands.

Conclusions: according to the conducted analyses, the world invasion of P. multivora most likely commenced from South Africa, which can be considered the center of origin of the species. The pathogen was then introduced to Australia, which acted as bridgehead population for Europe and North America. Our study highlights a complex global invasion pattern of P. multivora, including both direct introductions from the native population and secondary spread/ introductions from bridgehead populations.
\end{abstract}

Keywords: Biological invasion, Center of origin, Population diversity, Bridgehead effect, Demographic history

\section{Background}

Global trade in plants and plant products has inadvertently spread numerous plant pathogens worldwide, resulting in severe disease epidemics [1-3]. For many pathogens of agricultural crops, well-maintained

\footnotetext{
*Correspondence: tetyana.tsykun@wsl.ch
}

${ }^{3}$ Swiss Federal Research Institute WSL, Zürcherstrasse 111,

$\mathrm{CH}-8903$ Birmensdorf, Switzerland

Full list of author information is available at the end of the article databases exist, showing their current distribution [see Table 1 in 4]. With such information, the trade-associated risk of spreading the pathogen among countries or regions can be assessed [3, 4]. However, while information may be available for the geographic distribution of a pathogen, its center of origin may remain unknown [5]. Knowing where a pathogen has arisen and evolved is not only of academic importance but has concrete implications. For example, according to the enemy release hypothesis, the chances of finding natural enemies able to 
control a pathogen are higher in the native rather than in the introduced range [6]. Moreover, knowing the center of origin of a pathogen can help to understand the pathways of spread and to prevent or at least stop repeated introductions. The fewer the introductions, the lower the genetic diversity, and pathogens with low genetic diversity are less likely to overcome host resistance [7], increasing our chances to control or eradicate the pathogen. Similarly, for invasive pathogens in natural ecosystems, the lower the number of repeated introductions and the diversity of the pathogen, the higher the chance of finding a level of resistance within the naïve plant community [8].

Many Phytophthora species (Oomycetes, Stramenopila) are devastating plant pathogens in agriculture [9] and natural ecosystems [10], including those in the $P$. citricola sensu lato complex [11]. The complex includes several morphologically similar but phylogenetically distinct species described in the following order: P. citricola sensu stricto, $P$. plurivora [11], P. multivora [12], P. pini [13], P. capansis [14], P. pachypleura [15], P. acerina [16], $P$. caryae [17] and $P$. emzansi [18]. Many records initially ascribed to $P$. citricola s.l. have now been reassigned to other species within the complex, mainly $P$. plurivora and $P$. multivora, making its host range and species distribution narrower than previously thought $[11,12]$.

Phytophthora plurivora is a widespread pathogen in temperate forests of the northern hemisphere, where it is frequently associated with root and stem diseases [19, 20]. The species is also reported on ornamental plants in European and North American nurseries [21, 22], and it was shown P. plurivora had been introduced to North America from Europe [23]. Moderate genetic diversity and lack of genetic population structure in the European population suggested an introduced origin, but due to incomplete sample collection, the centre of origin of the species could not be determined. In the northern hemisphere, $P$. multivora is reported to be rare and somewhat restricted to nurseries and urban plantations [24], suggesting a relatively recent introduction.

Phytophthora multivora was the first pathogenic Phytophthora species to be described from natural ecosystems in Australia. As it is widely distributed and associated with significant plant mortality, it was initially hypothesized to be native to Western Australia [12]. The species has since been reported on five continents, usually associated with diseases of woody plants. Reports from natural ecosystems [12, 25, 26], production orchards [27-30] and restoration sites [31,32] are from Mediterranean climates, whereas reports from ornamentals and the nursery trade extend into temperate regions of Europe [19], North America [33] and Japan [34, 35].
The global distribution of $P$. multivora brings into doubt the assumption that it is native to Western Australia.

Investigations about the genetic diversity and comparative analysis of population structure combined with a coalescent approach can decipher demographic history and gene flow among geographic populations, which may shed light on the possible origin of a species [23, 36-38]. Thus, in order to unravel the worldwide invasion history of $P$. multivora, we obtained a global collection of isolates from North America, Europe, Africa, Australia, the Canary Islands, New Zealand, and examined them with two sets of genetic markers; firstly, 10 single sequences repeats (SSR) and secondly sequences of three mitochondrial and three nuclear loci. Specifically, we addressed the following questions. (1) How genetically diverse are the studied populations? (2) How does the genetic structure differ among the populations? (3) What was the most likely demographic history of the populations' establishment? (4) What is the geographic origin of the isolate harboring the ancestral state sequences according to coalescent phylogenetic analysis? and (5) What was the most likely global invasion history of $P$. multivora?

\section{Results}

\section{Loci and multilocus genotypes}

All 10 screened SSR loci were formally polymorphic, i.e. minor allele frequencies were $>5 \%$ in the global population and $>1 \%$ in each geographic population, and minor alleles were observed in more than two samples per geographic population. Pairwise linkage disequilibrium and deviation from Hardy-Weinberg equilibrium were not consistent across loci and populations (Supplementary Fig. S1-2). Hence, all loci were considered for population genetic analyses. However, the

Table 1 Multilocus genotype (MLG) summary statistics inferred from 10 SSR loci in six populations (South Africa, Australia, Canary Islands, Europe, New Zealand, and North America) and the global population of Phytophthora multivora

\begin{tabular}{llllll}
\hline Population & Samples & MLG $^{\mathbf{a}}$ & $\mathbf{~} M L G^{\mathbf{b}}$ & $\mathbf{c M L G}^{\mathbf{c}}$ & $\mathbf{i M L G}^{\mathbf{d}}$ (\%) \\
\hline South Africa & 43 & 34 & 9 & 5 & $29(85)$ \\
Australia & 198 & 54 & 7 & 10 & $44(81)$ \\
Canary Islands & 26 & 3 & 2 & 3 & 0 (n.a.) \\
Europe & 12 & 7 & 6 & 5 & $2(29)$ \\
New Zealand & 20 & 18 & 10 & 0 & $18(100)$ \\
North America & 7 & 3 & 3 & 3 & $0(0)$ \\
Global population & 306 & 119 & 7 & 10 & $93(78)$ \\
\hline
\end{tabular}

${ }^{a}$ Number of MLGs in each population

${ }^{b}$ Expected number of MLGs at the largest shared sample size (here 7 samples in North America) based on a rarefaction;

' Number of MLGs also present in other populations;

${ }^{d}$ Number MLGs unique to the specific population (in brackets as a percent of the occurring MLGs) 
polymorphism of SSR loci was generally very low, with six out of the 10 loci showing a distinct dominant allele with a frequency of more than $72 \%$ in the global population. Less than $0.04 \%$ of missing data (i.e. no allele at a specific locus) were observed among the 306 isolates screened; thus, all multilocus genotypes (MLGs) were included in the study.

Based on the number of expected MLGs (see eMLG in Table 1), New Zealand, South Africa, and Australia were the most diverse populations. Only 10 MLGs among 119 MLGs were present in more than one population worldwide, and remarkably, all those MLGs occurred in Australia. Whereas 18 MLGs recovered in New Zealand were unique to this population.

We successfully sequenced three mitochondrial regions NADHI, coxI and coxIGS. The coxI and coxIGS were trimmed and concatenated for the downstream analysis into mitochondrial gene region $\mathrm{COI}$, and three nuclear loci (ASF, ENOLASE, and HSP90) loci for 93 P. multivora DNA isolates. Additionally, we cloned 24 ENOLASE gene variants from 8 isolates and 10 HSP90 gene variants from 3 isolates. Alignment of sequences, including cloned loci, revealed 106 informative nucleotide sites in 113 genotypes. Clone-censored per geographic population data set resulted in 60 unique genotype sequences used for further phylogeographic investigation. Sequence and site diversities between mitochondrial and nuclear gene regions were comparable; however, they differed substantially among populations (Table 2). The highest estimates of diversity were observed in the South African populations, followed by the Australian and New Zealand populations. On the other side, populations from the Canary Islands and North America revealed the lowest diversity values.

\section{Population diversity and structure}

The diversity and genetic structure of the global P. multivora population were assessed using data from 10 SSR loci and 119 MLGs (clone-corrected data per population). The highest diversity estimates (i.e. number of MLGs, allelic richness, and diversity indexes) were observed in the South African and Australian populations, followed by the New Zealand population (Table 3). These three populations also harbored private alleles (3-5 per population). In contrast, besides the lack of private alleles, the Canary Islands, European, and North American populations each showed relatively low diversity estimates. However, MLGs found in Europe showed slightly higher diversity than MLGs from the Canary Islands or North America (Table 3).

All populations showed no heterozygosity, except the population in Australia in which two MLGs were heterozygous in five loci each. The index of association $\left(\mathrm{I}_{\mathrm{A}}\right)$ and the standardized index of association (rD) indicated a significant $(P<0.05)$ non-random association of loci and departure from panmixia in all populations (Table 3).

Significant population differentiation $\left(\mathrm{F}_{\mathrm{ST}}=0.14-0.32\right.$, Table 4) was observed among all populations and New Zealand. This specific population showed the most distant genetic relatedness to the Canary Islands and North American populations and was equally close to the $P$. multivora populations from South Africa and Australia $\left(\mathrm{F}_{\mathrm{ST}}=0.14\right)$. The lowest but statistically significant differentiation $\left(\mathrm{F}_{\mathrm{ST}}=0.05\right)$ was observed between the South African and Australian populations. The European population did not show any statistically significant differentiation with the other populations but New Zealand.

Clustering of $P$. multivora MLGs from different populations was retrieved with a discriminant analysis of

Table 2 The genetic diversity of nuclear and mitochondrial loci of Phytophthora multivora in the six populations (South Africa, Australia, Canary Islands, Europe, New Zealand, and North America) analyzed in this study

\begin{tabular}{|c|c|c|c|c|c|c|c|}
\hline $\begin{array}{l}\text { Population } \\
\text { Estimates }^{\text {a }}\end{array}$ & Global & South Africa & Australia & Canary Islands & Europe & New Zealand & North America \\
\hline $\begin{array}{l}\text { Number of } \\
\text { Sequences }\end{array}$ & 113 & 31 & 37 & 7 & 15 & 15 & 8 \\
\hline Length, bp & \multicolumn{7}{|c|}{3370 (m: 1192; n: 2176) } \\
\hline $\begin{array}{l}\text { Polymorphic } \\
\text { sites }(N)\end{array}$ & 10 (m: 41; n: 65) & 73 (m: 27; n: 46) & 41 (m: 16; n: 25) & $4(m: 2 ; n: 2)$ & 29 (m: 11; n: 18) & 25 (m: 12; n:13) & $4(m: 1 ; n: 3)$ \\
\hline $\mathrm{Pi}^{\mathrm{b}}$ & $\begin{array}{l}0.0036 \text { (m: } \\
0.0038 ; n: 0.0034)\end{array}$ & $\begin{array}{l}0.0047 \text { (m: } \\
0.0047 ; \mathrm{n}: 0.0046)\end{array}$ & $\begin{array}{l}0.0035 \text { (m: } \\
0.0037 ; \mathrm{n}: 0.0034)\end{array}$ & $\begin{array}{l}0.0003 \text { (m: } \\
0.0065 ; \mathrm{n:} 0.0001)\end{array}$ & $\begin{array}{l}0.0283 \text { (m: } \\
0.0032 ; \mathrm{n}: 0.0027)\end{array}$ & $\begin{array}{l}0.0024 \text { (m: } \\
0.0028 ; \mathrm{n}: 0.0022)\end{array}$ & $\begin{array}{l}0.0004(\mathrm{~m}: 0.0043 \\
\mathrm{n}: 0.0003)\end{array}$ \\
\hline$\theta^{c}$ & $\begin{array}{l}16.44 \text { (m: } 6.43 ; n: \\
10.02)\end{array}$ & $\begin{array}{l}13.72 \text { (m: } 5.19 ; \mathrm{n}: \\
8.53)\end{array}$ & $\begin{array}{l}7.54 \text { (m: 2.87; n: } \\
4.67)\end{array}$ & $\begin{array}{l}1.03 \text { (m: 0.51; } \mathrm{n}: \\
0.51)\end{array}$ & $\begin{array}{l}6.43 \text { (m: 2.36; } \mathrm{n}: \\
4.07)\end{array}$ & $\begin{array}{l}5.36 \text { (m: } 2.57 ; \mathrm{n}: \\
2.79)\end{array}$ & $\begin{array}{l}0.99 \text { (m: 0.25; n: } \\
0.74)\end{array}$ \\
\hline
\end{tabular}

${ }^{a}$ For each diversity estimate, the total value and in brackets the values for mitochondrial loci sequences ( $m$; COI and NADHI) and for nuclear loci sequences ( $n$; ASP, ENOLASE, HSP90) are given

${ }^{\mathrm{b}}$ Nucleotide diversity per site

'Theta per sequence [39] 
Table 3 Summary statistics inferred from 10 SSR loci in the six populations (South Africa, Australia, Canary Islands, Europe, New Zealand, and North America) of Phytophthora multivora analyzed in this study

\begin{tabular}{|c|c|c|c|c|c|c|}
\hline Population & South Africa & Australia & Canary Islands & Europe & New Zealand & North America \\
\hline Samples (N) & 43 & 198 & 26 & 12 & 20 & 7 \\
\hline $\mathrm{MLGs}^{1}(\mathrm{~N})$ & 34 & 54 & 3 & 7 & 18 & 3 \\
\hline $\mathrm{Ar} \pm \mathrm{SD}^{2}$ & $2.78 \pm 0.68$ & $2.64 \pm 0.69$ & $1.70 \pm 0.46$ & $2.16 \pm 0.73$ & $2.52 \pm 0.83$ & $1.60 \pm 0.66$ \\
\hline$(\mathrm{Ar} \pm \mathrm{SD})$ & $(4.3 \pm 1.52)$ & $(4.18 \pm 1.45)$ & - & - & $(3.70 \pm 1.68)$ & - \\
\hline $\mathrm{Pa}^{3}$ & 3 & 5 & 0 & 0 & 4 & 0 \\
\hline $\mathrm{H}^{4}$ & 3.53 & 3.99 & 1.10 & 1.95 & 2.89 & 1.10 \\
\hline$\Lambda^{5}$ & 0.97 & 0.98 & 0.67 & 0.86 & 0.94 & 0.67 \\
\hline $\mathrm{Hexp}^{6}$ & 0.60 & 0.56 & 0.37 & 0.43 & 0.51 & 0.29 \\
\hline Hobs $^{7}$ & 0.00 & 0.02 & 0.00 & 0.00 & 0.00 & 0.00 \\
\hline $\mathrm{I}_{\mathrm{A}}^{8}$ & 0.91 & 0.88 & 3.43 & 1.30 & 1.05 & 3.00 \\
\hline (p-value) & $(0.00)$ & $(0.00)$ & $(0.01)$ & $(0.00)$ & $(0.00)$ & $(0.00)$ \\
\hline $\mathrm{rD}^{9}$ & 0.10 & 0.10 & 0.57 & 0.16 & 0.12 & 1.00 \\
\hline ( $p$-value) & $(0.00)$ & $(0.00)$ & $(0.02)$ & $(0.00)$ & $(0.00)$ & $(0.03)$ \\
\hline
\end{tabular}

${ }^{1}$ Number of multilocus genotypes in each population;

${ }^{2}$ Mean allelic richness and standard deviation computed per locus and rarefied to the population with the lowest sample size (North America). In brackets, mean allelic richness computed for populations with more than $10 \mathrm{MLGs}$;

${ }^{3}$ Private alleles observed in each population;

${ }^{4}$ Shannon-Weiner diversity index;

${ }^{5}$ Simpson's diversity index;

${ }^{6}$ Nei's gene diversity (expected heterozygosity);

${ }^{7}$ Observed heterozygosity;

${ }^{8}$ Index of association for each population with $P$-value (in brackets) resulting from a one-sided permutation test;

${ }^{9}$ Standardized index of association for each population with $P$-value (in brackets) resulting from a one-sided permutation test

Table 4 Pairwise $\mathrm{F}_{\mathrm{ST}}$-values inferred from 10 SSR loci between the six P. multivora populations (South Africa, Australia, Canary Islands, Europe, New Zealand, and North America) analyzed in this study

\begin{tabular}{llllll}
\hline Population (MLG) & South Africa (34) & Australia (54) & Canary Islands (3) & Europe (7) & New Zealand (18) \\
\hline Australia (54) & $0.05^{2}(<0.01)$ & & & \\
Canary Islands (3) & $0.08(0.46)$ & $0.11(0.26)$ & & & \\
Europe (7) & $0.11(0.05)$ & $0.04(0.38)$ & $0.08(0.62)$ & $0.25(<0.01)$ \\
New Zealand (18) & $0.14(<0.01)$ & $0.14(<0.01)$ & $0.32(0.01)$ & $0.06(0.58)$ & $0.31(0.01)$ \\
North America (3) & $0.17(0.10)$ & $0.07(0.47)$ & $0.35(0.22)$ & \\
\hline
\end{tabular}

${ }^{1}$ Number of multilocus genotypes in each population

${ }^{2}$ In brackets, the $P$-value resulting from a one-sided permutation test

principal components (DAPC, Fig. 1) defined from clonecorrected data (119 MLGs). According to the lowest root mean squared error and highest mean of successful reassignments with 1000 replicates (cross-validation), 25 of the 47 computed PCs were used to build discriminant functions. We observed a relatively distant and wellcentered clustering of MLGs from the three most diverse populations (Fig. 1). Specifically, the New Zealand population discriminated along the first axis from the Australian population and along the second axis from the South African population. The other three less diverse populations (North America, Europe, and the Canary
Islands) clustered within those centers and were mainly associated with Australian MLGs. Random MLGs from the European and Canary Islands populations were associated with the New Zealand and South African MLG clusters.

Overall, multivariate discriminant analysis and the StRUCTURE Bayesian analysis showed congruent results. In the STRUCTURE analysis, considering alteration of assignments in admixed populations (Supplementary Fig. S3), the $\log$-likelihood increasing up to 20 clusters (Fig. 2B) and the second-highest difference of the loglikelihood among different $\mathrm{K}(\Delta \mathrm{K}$ peak at $\mathrm{K}=4$, Fig. $2 \mathrm{~A})$, 


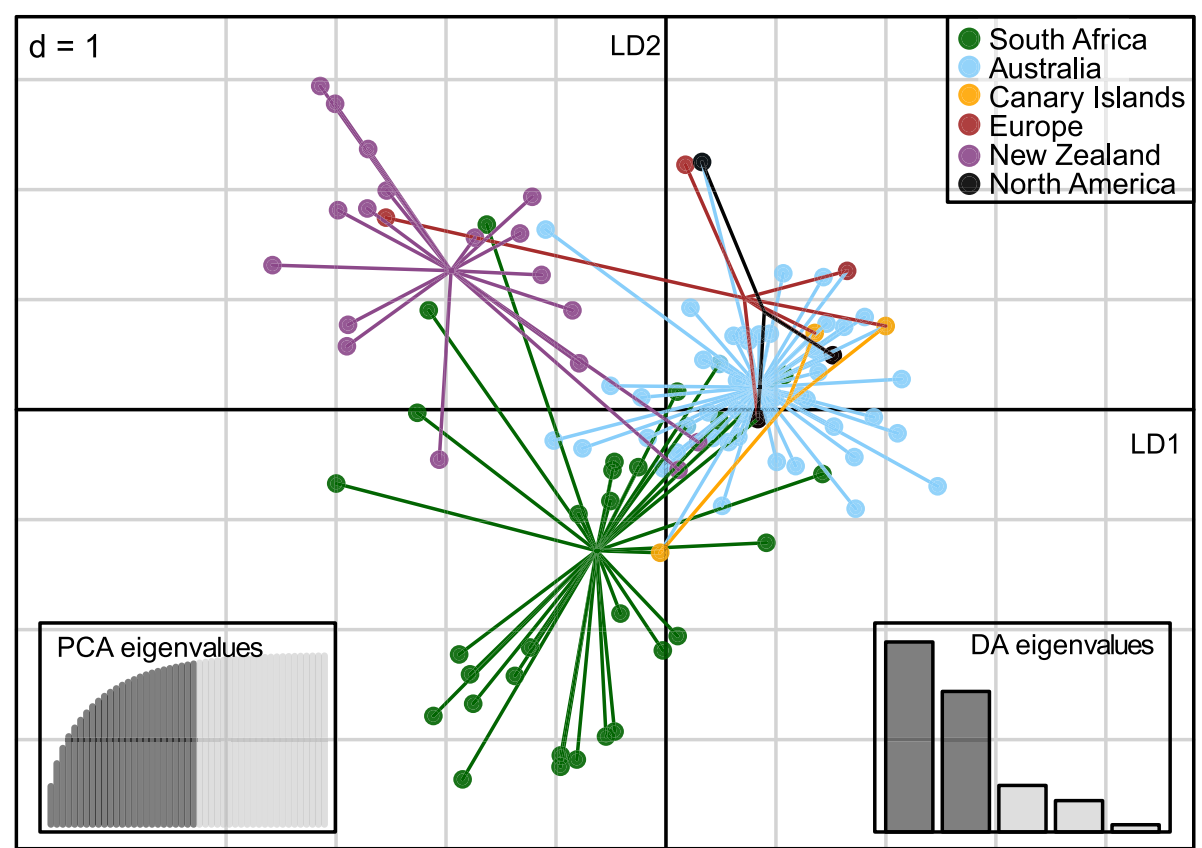

Fig. 1 DAPC results were computed with the 119 MLGs detected in the six populations of Phytophthora multivora (South Africa, Australia, Canary Islands, Europe, New Zealand, and North America) analyzed. MLGs are color-coded by population, as indicated on the top of the scatterplot. Scatterplots represent the distribution of individual MLGs (symbols) along the first two linear discriminants. The cross-validated number of the principal components and selected linear discriminants used for the analysis is shown in dark color in the bar plots on the bottom left and right of the scatterplot, respectively

we assumed four clusters as reasonable to best describe the genetic structure in the global population of $P$. multivora (Fig. 2C). MLGs from South Africa were equally assigned to all four defined genetic clusters. The Australian population was co-dominated by MLGs assigned to the fourth (yellow) cluster followed by the third (grey) cluster. The remaining two clusters (blue and yellow) were least represented in this particular population. MLGs from New Zealand were mostly assigned to the first (orange) cluster with minor admixture of the fourth (yellow) cluster and two MLGs assigned to the second (blue) cluster. Finally, P. multivora populations from Europe and the Canary Islands were dominated by the third (grey cluster), whereas the North American population included two MLGs assigned to the fourth (yellow) and one to the third (grey) cluster. Noteworthy, no admixed MLGs (i.e. assigned partially to different clusters) were observed in these last three populations.

\section{Likelihood population history}

Considering the high diversity estimates, relatively low $\mathrm{F}_{\mathrm{ST}}$ values, three-center clustering in the multivariate discriminant analysis, and diverse genetic population structure in the South African, Australian, and New Zealand populations, we assumed these populations were older and likely source of the other three populations. Indeed, populations of Europe, the Canary Islands, and North America showed a lower diversity and no or few private alleles and unique MLGs.

Six different scenarios of the demographic history (see details on the competing scenario in Supplementary Notes 1, Fig. S4-5, Table S2-3) were tested with the Approximate Bayesian Computational (ABC) analysis to define the source population among the South African, Australian, and New Zealand populations. The highest posterior probabilities with non-overlapping 95\% Cis, inferred from 500 simulated data closest to the observed using a direct approach (Supplementary Fig. S5, Table S2) and 1000 simulated data closest to the observed with a linear discriminant transformation (Fig. 3A left) of the summary statistic values were computed for the fifth scenario (Fig. 3A right, Supplementary Table S2). In this particular scenario, we assumed that at nominal time $\mathrm{t} 1$, two populations of a small effective size were introduced to New Zealand and Australia from the South African population. These two initial populations (AUb and NZb in Fig. 3A right) independently developed during the establishing time $\mathrm{t} 1-\mathrm{db}$ and resulted in the current populations (AU and NZ) at nominal time t0. We intentionally did not speculate about quantitative estimates of the time and effective population sizes of the historic populations 


\section{(A)}

Delta $(\mathrm{K})$

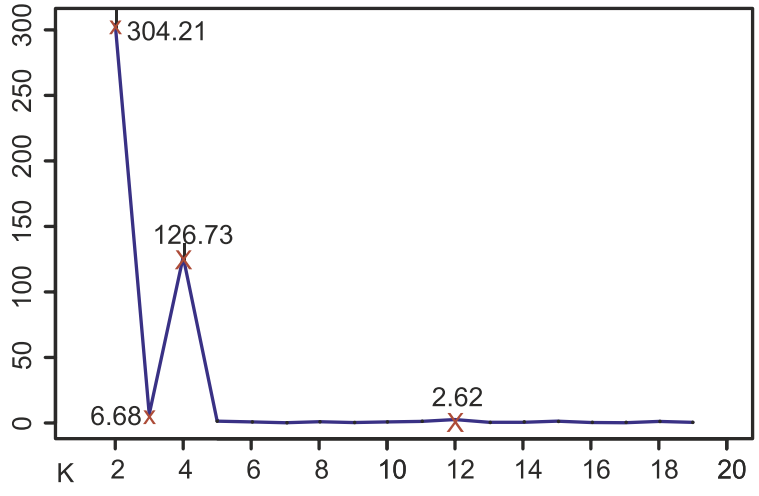

(B)

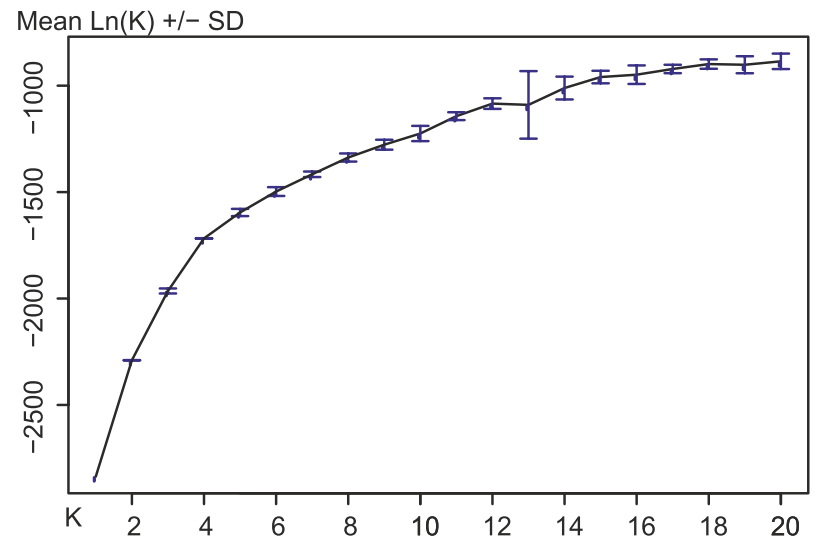

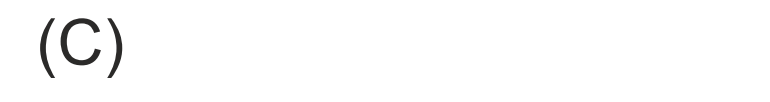
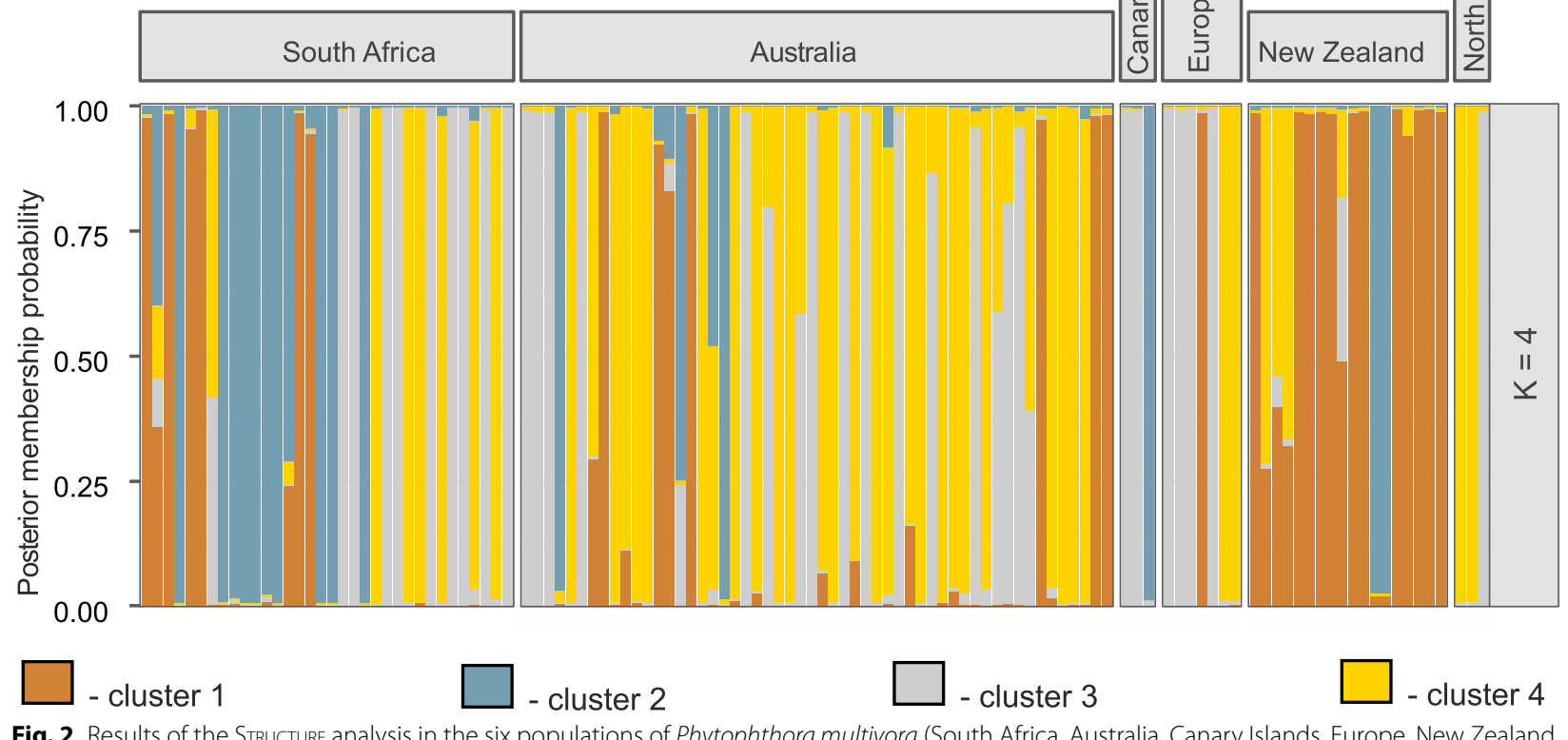

Fig. 2 Results of the Structure analysis in the six populations of Phytophthora multivora (South Africa, Australia, Canary Islands, Europe, New Zealand, and North America). A Graph representing $\triangle K$, with the four most considerable changes marked with a brown cross. B Graph representing the mean log-likelihood values ( \pm standard deviation) for different numbers of clusters. The barplot represents the average estimated membership probability (y-axis) of an MLGs assigned to a specific cluster (indicated by specific color) among four clusters selected to describe the global population structure

retained in the $A B C$ analysis. This is because of the difficulties in realistically addressing generation time or individuals' number in oomycete species like P. multivora. Despite the possible uncertainty in the analysis of the specific quantitative results, the topology of our $A B C$ analysis clearly showed the South African population is most likely the global source and place of origin of the species, and the two populations of New Zealand and Australia directly originated from it.

The second ABC step supported (Fig. 3B left) the fourth scenario (see details on the competing scenario in Supplementary Notes 1, Fig. S6-7, Table S4). This specific scenario suggested after the establishment of the Australian population, some MLGs were introduced to North 


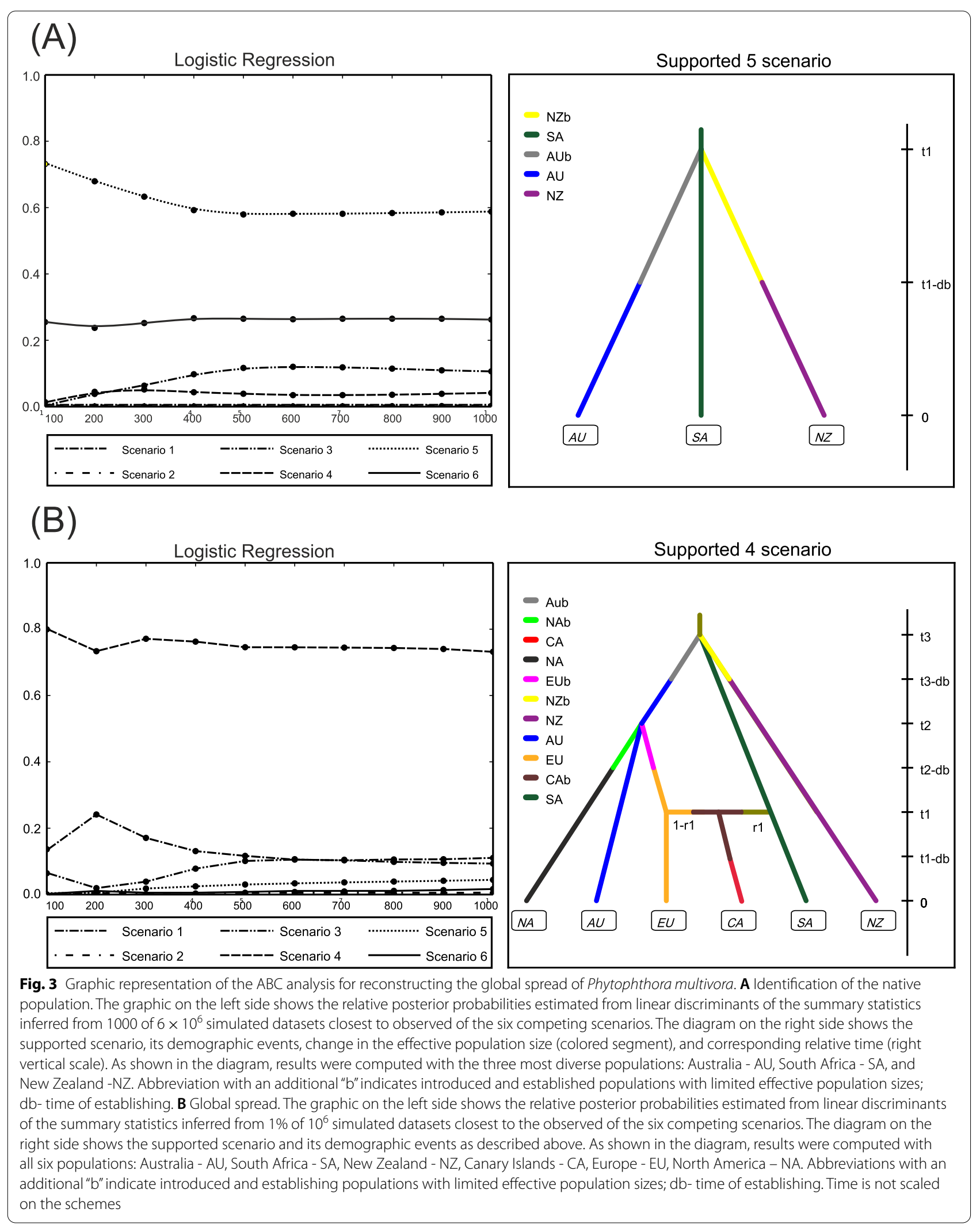


America (specifically to the US) and Europe around the same time, nominally at time $\mathrm{t} 2$. These populations (NAb and $\mathrm{EUb}$ ) of a limited effective size independently developed further, resulting in the populations sampled at time t0. After the establishment of the European population, at time $\mathrm{t} 1$ some MLGs were presumably introduced from both Europe and the native South African population to the Canary Islands, where they founded a relatively young and admixed population $\mathrm{CAb}$ that developed to the sampled population CA in Fig. 3B (left diagram).

\section{Bayesian phylogeographic analyses}

The best-fit models for each of the sequenced loci, specifically COI (concatenated coxI and coxIGS) and NADHI (mtDNA) as well as ASF, ENOLASE, HSP90 (nDNA), were as follows: HKY (Hasegawa-Kishino-Yano) for both mtDNA loci, JC69 (Jukes-Cantor) for the ASF locus and TN93 (Tamura-Nei) for the other two nDNA loci. Both Bayesian coalescent analysis we conducted, i.e. StarBeast with multilocus mitochondrial data and phylogeographic MASCOT with three nuclear and three mitochondrial loci, showed with high posterior probabilities that MLGs from South Africa are likely representing an ancestral lineage to the current global population of $P$. multivora (Fig. 4A, B). The genealogy reconstructed with the StarBeast method and scaled to time according to the $2.4 \times 10^{-6}$ per site and per year [40] substitution rate for mitochondrial genome showed that divergence of South African and Australian populations (Fig. 4A) might have occurred $300-400$ years ago, while the divergence of Australian and others populations analyzed in the study started at the end of the nineteenth century. Results of MASCOT indicated South Africa as the most common location of the root node with a posterior probability (PP) of 0.996 against $<0.004$ for any other location (Fig. 4B). The maximum-clade-credibility tree discriminated further MLGs into two major clades, for both of which South Africa was determined as ancestral location (PP 0.99 vs. $<0.011$ for other populations). In the first clade from above (Fig. 4B), the Australian lineage diverged from the South African sister clade. This new (blue) clade harbored most MLGs from New Zealand, North America, the Canary Islands and Europe and, with high posterior probability support $(0.99$ vs $<0.002$ for others populations), had Australia as the source location. However, three MLGs from Europe were more closely related to South African MLGs (Fig. 4B). In addition, we observed high estimates of migration from South Africa to Europe (Supplementary Table S5); suggesting a direct origin of part of the European P. multivora population from the ancestral South African population. A few Australian MLGs did not cluster within the major (blue) Australian clade, and might be the consequence of repeated introductions of $P$. multivora to Australia, mainly from South Africa.

\section{Discussion}

Our analyses shed light on the population diversity, reproductive biology, and invasion history of Phytophthora multivora. We detected substantial genotypic diversity with polymorphic SSR markers, i.e. 119 MLGs among the 306 isolates analyzed. Nevertheless, only two MLGs, both occurring in Australia, were heterozygous. The homothallic mating system of $P$. multivora could explain the lack of heterozygotes. Similar extremely low heterozygosity was observed in populations of other homothallic Phytophthora species, e.g. in P. sojae [41] and P. plurivora [23]. Homothallism implies self-fertilization during sexual reproduction (i.e. oospore formation), which leads to extensive inbreeding and the reduction of heterozygosity in a population [42]. However, homothallic species can sometimes outcross, and heterothallic species can sometimes self-fertilize [43]. We also detected positive and significant indexes of association $\left(\mathrm{I}_{\mathrm{A}}\right.$ and $\left.\mathrm{rd}\right)$, indicating nonrandom association of loci. Among several reasons for the deviation from the random association of gametes (panmixia), the most common for oomycetes or fungi are asexual and clonal reproduction [44]. Indeed, P. multivora, like many other species in the genus, grows clonally and produces asexual sporangia, releasing zoospores. Zoospores dispersed through the soil water are the main infective propagules $[45,46]$. However, the predominance of asexual reproduction would also lead to lower genotypic diversity and higher heterozygosity [44]. Hence, the extreme lack of heterozygosity, substantial MLG diversity, and deviation from panmixia, suggest $P$. multivora readily propagates both from oospores through

(See figure on next page.)

Fig. 4 Maximum clade credibility trees of Phytophthora multivora, each was inferred from 9001 Bayesian trees that were sampled among $2 \times 10^{7}$. Support of the phylogenetic clades with PP> 0.7 is shown in the nodes. A Generalized to population level phylogeny was reconstructed using sequences of three mitochondrial (coxl and coxIGS and NADHI) of 60 P. multivora samples from the six populations (South Africa, Australia, Canary Islands, Europe, New Zealand, and North America). Time is scaled according substitution rate $2.4 \times 10^{-6}$ per site and per year on the $x$-axis. B Phylogeny was reconstructed using sequences of three mitochondrial (coxl and coxIGS and NADHI), and three nuclear loci (ASF, ENOLASE, and HSP90) of 60 P. multivora samples from the six populations (South Africa, Australia, Canary Islands, Europe, New Zealand, and North America). Samples are named as follows: population, strain's ID, and number when a cloned variant of a gene was present. Colors of branches indicate the most common location of the node with PP $>0.98$ of the geographic origin of each clade 
(A)

(B)
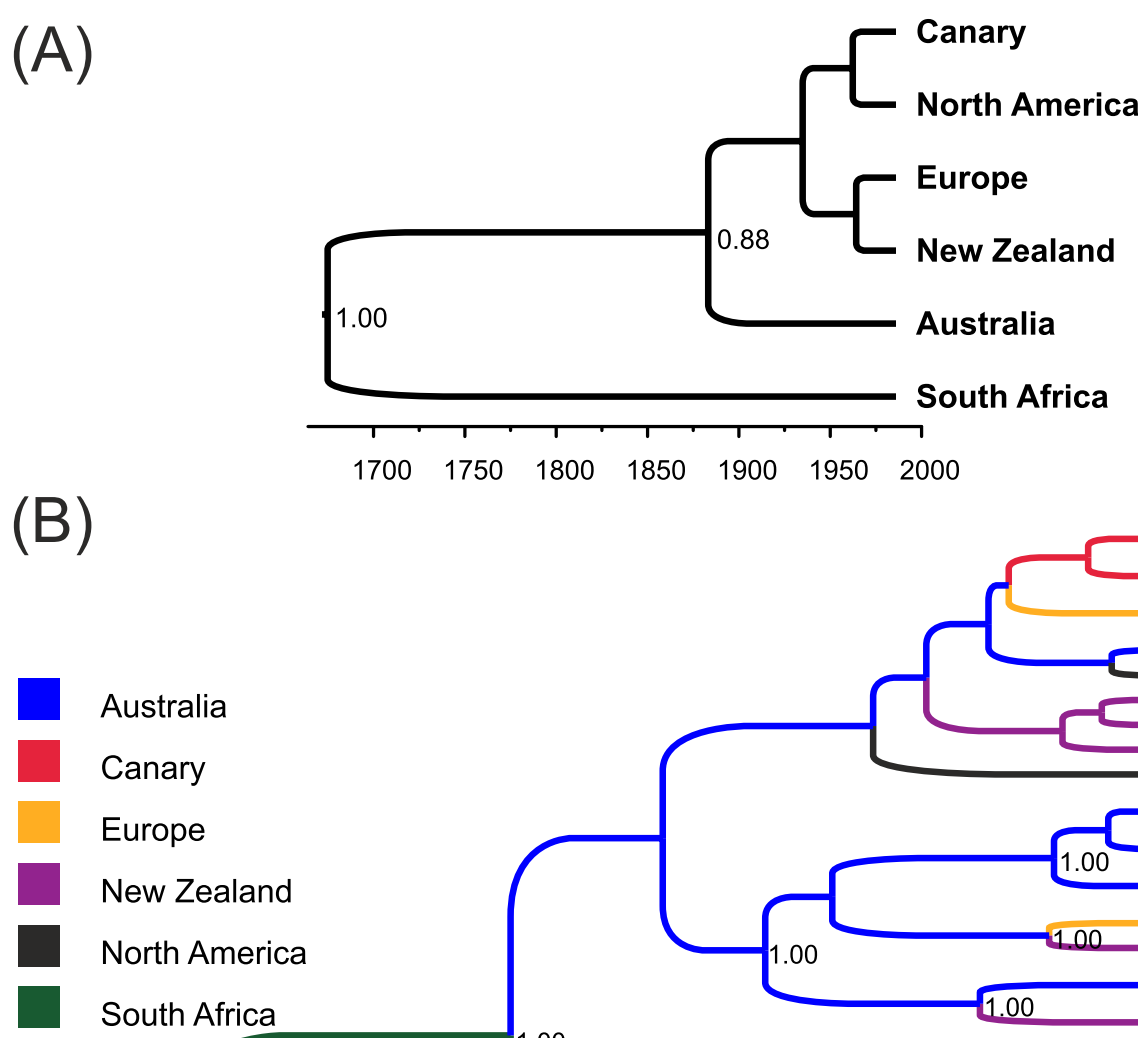

Australia

Canary

Europe

New Zealand

North America

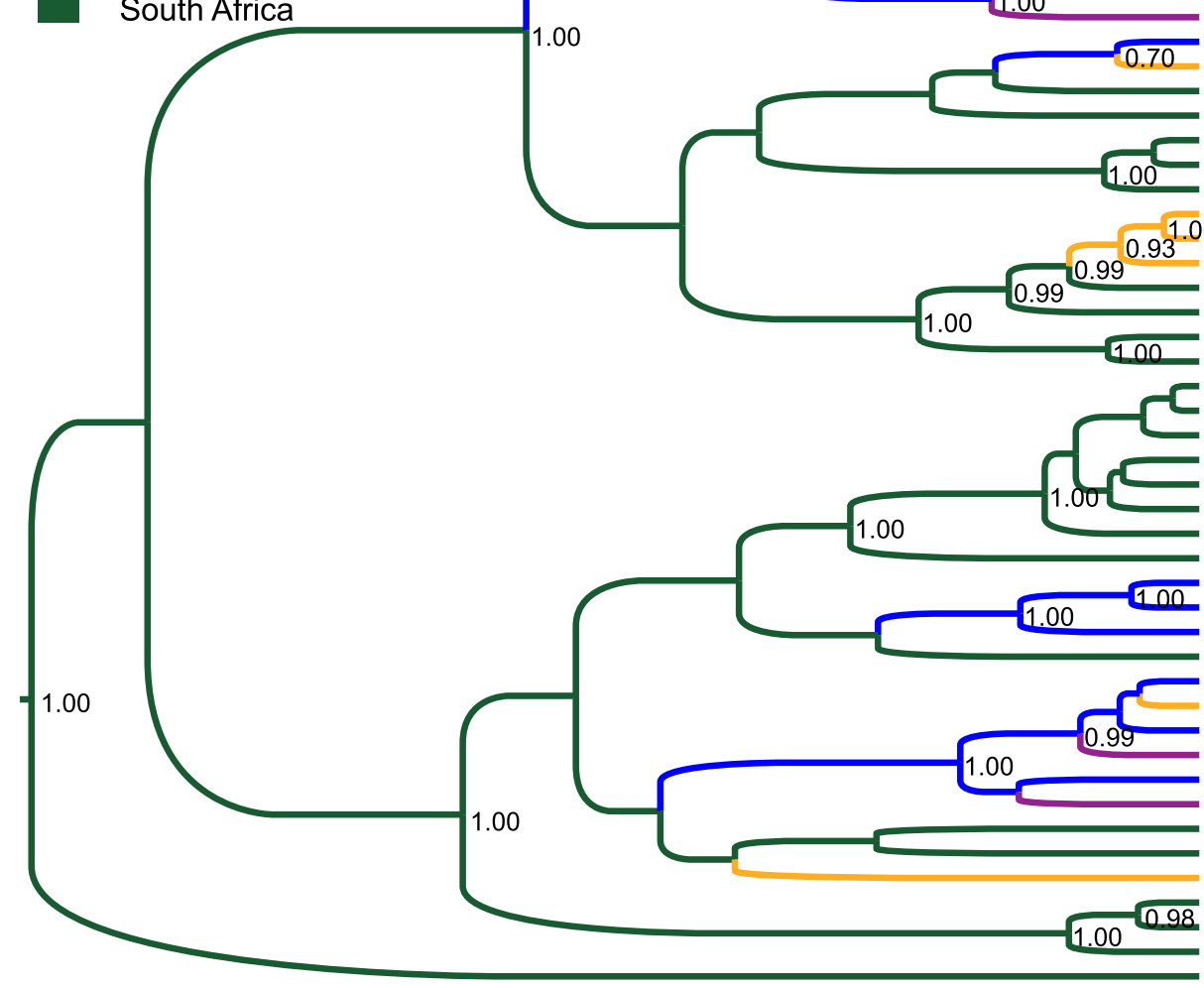

South Africa

0.85

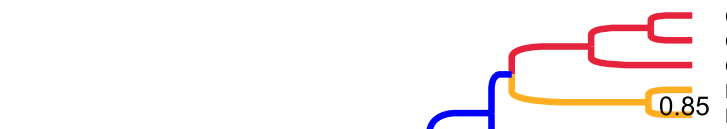

Canary_CAN01

Canary_CAN06

Canary_CAN11

Europe EU05

Europe EU06

Australia AUVHS21205

NorthAmerica_US01

NewZealand_NZ2751

NewZealand NZCBS113347

NewZealand NZ011702

NorthAmerica US03

Australi AUEA01

Australia_AUVHS22575

Australia_AUDDS3700

Australia AUHSA1153

Australia_AUHSA2297

Europe_EU03

NewZealand NZ3377

Australia AUEA03

Australia AUEA04-6

NewZealand_NZ0951

Australia_AUVHS15316

Europe_EU09

SouthAfrica_SACMW 35250

SouthAfrica SACMW 35280

SouthAfrica_SACMW33966

SouthAfrica_SACMW33968 SouthAfrica_SACMW33964

Europe_EU01

Europe EU02-1

Europe EU10

SouthAfrica SACMW35234

SouthAfrica SACMW 35512

SouthAfrica_SACMW33959 SouthAfrica_SACMW33961

SouthAfrica_SACMW35209

SouthAfrica_SACMW35221

SouthAfrica SACMW35209-3

SouthAfrica SACMW35209-1

SouthAfrica_SACMW35221-1 SouthAfrica_SACMW35221-2

SouthAfrica_SACMW35221-3

SouthAfrica SACMW 35279

Australia AUWAC13200

Australia AUWAC13201

Australia_AUWAC13204

SouthAfrica_SACMW35514

Australia AUWAC13203

Europe_EU13

Australia AUVHS20916

NewZealand NZ3378

Australia AUWAC13205

NewZealand_NZ3448

SouthAfrica_SACMW33963

SouthAfrica SACMW 35216

Europe_EU11

SouthAfrica_SACMW 35236

SouthAfrica_SACMW35236-1

SouthAfrica_SACMW35241

SouthAfrica_SAP1817

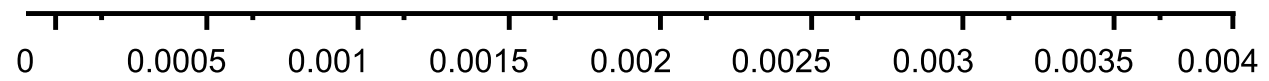

Fig. 4 (See legend on previous page.) 
homothallic self-fertilization and asexual zoospores, but gene flow among studied populations is restricted.

Our study revealed relatively high genetic diversity with both genetic markers in the three $P$. multivora populations, specifically in South Africa, Australia, and New Zealand. Correspondingly, all MLGs clustered around three centers associated with these geographic locations in the multivariate non-parametric analysis (DAPC in Fig. 1), suggesting those populations are older than others and are most likely already well established. In contrast, the other populations of North America, Europe, and the Canary Islands were substantially less diverse. A few MLGs from these populations are not unique, but occurred in three other populations, and clustered predominantly around the Australian center, suggesting their secondary origin.

Phytophthora multivora became known worldwide due to its distribution and devastating effect on woody plants in Western Australia [12, 24]. Later, this species was discovered widespread in soil, streams, and the rhizosphere of asymptomatic vegetation in South Africa [25]. The same study revealed high genetic diversity of the South African population, similar to the population of West Australia. However, in South Africa, unlike in Australia, $P$. multivora was not associated with any disease outbreaks or extensive plant mortality [25, 47-49], suggesting a long-term co-evolution between native tree species and the pathogen. The species was also retrieved from waterways and soil of disease foci in New Zealand. However, its ecological role is still unclear [49-51]. In the current study, the genetic diversity of $P$. multivora was slightly lower in New Zealand than in South Africa and Australia. Noteworthy, the New Zealand population showed the highest number of unique genotypes and highest $\mathrm{F}_{\mathrm{ST}}$ values, indicating the most distant relatedness to other populations in the world. This might reflect an ancient introduction from a more diverse source population and then an isolated evolution of the New Zealand population. Such an introduction might be a consequence of the uncontrolled but considerable intraregional trades of woody plants and seedlings between New Zealand and Australia, or/and intercontinental import directly from South Africa during colonization of both Australia and New Zealand. During colonization of Australia and New Zealand, Capetown was a port of call on the voyage from Europe [52]. The spread of many known forest pests and pathogens was predominantly assisted by human activity under fast globalization [53]. For example, $P$. ramorum and Cryphonectria parasitica were introduced to North America and Europe through nursery stock import $[54,55]$, P. cinnamomi invasion was associated with the trade of agricultural commodities [38], the trade of wooden logs contributed to Dutch elm disease caused by Ophiostoma ulmi and O. novo-ulmi $[53,56]$, and the use of wooden packages for long-distance transportation is responsible for the global spread of the Asian longhorned beetle (Anoplophora glabripennis) [57]. Furthermore, even traded forest seeds can be a source of pathogens $[58,59]$. The upsurge of invasions raises the urgent need to consider global quarantine management [60].

The global invasion of P. multivora most likely commenced from South Africa. We detected the most complex genetic structure in this particular population, i.e. local MLGs were assigned to all four genetic clusters defined in STRUCTURE analysis in nearly equal proportion (Fig. 2), congruent with high diversity estimates of summary statistics. The Australian and New Zealand populations showed co-dominant clusters, suggesting genetic diversity was only partially preserved in those populations over time. These observations were confirmed by the approximate Bayesian computation analysis $(A B C)$ and suggested the Australian and New Zealand populations originated from South Africa and experienced an establishing time of limited effective sizes. During the lag invasion phase, some specific genotypes may go lost due to natural selection or by chance (drift) in a population, while others may successfully spread. Alternatively, only a few specific genotypes were initially introduced in each of two populations, or as suggested by $\mathrm{ABC}$ analyses, there was no direct introduction from South Africa to New Zealand but via the bridgehead through Australia. In this case, most likely, the limited number of genotypes arrived in New Zealand from Australia and established a new, less diverse population. This invasion scenario is supported by the relatively lower diversity estimates and the presence of only two genetic clusters with non-admixed MLGs (Fig. 2) in New Zealand compared to the presence of all four in Australia. Similar to our study on P. multivora, the bridgehead effect was reported for many globally dispersed invasive pests and pathogens of plants [61-65]. The bridgehead effect describes the scenario where an invasive pest is first established in a new area after which secondary spread occurs, leading to the foundation of new invasive populations [63]. Frequently, due to global human trades and movement, the step population is as distant as a different continent.

Overall, the results obtained with Bayesian coalescent analyses of both nuclear and mitochondrial sequences confirmed our findings in population structure and $A B C$ history analysis of 10 SSR genetic markers. In particular, both analyses are in accordance with South Africa being the center of origin of $P$. multivora, and Australia being the primary distributor of the species worldwide. Multilocus coalescent genealogy based on mitochondrial loci 
and scaled to time showed that South African and Australian populations might had diverged 300-400years ago, which corresponds to the period of European exploration of Australia and Dutch colonization of South Africa. The secondary spread of $P$. multivora from the bridgehead population in Australia and the consequent establishment of new populations throughout the world might had started at the end of the nineteenth century during intensification of global trade and travels, which facilitate introduction of alien pathogens in new ecosystems [66]. Hence, P. multivora is another plant pathogen first described outside its center of origin due to the extensive damage caused on naïve species in the introduced range. Likewise, $P$. infestans, the responsible for the Irish potato famine (1845), originated most likely from Mexico [40]. Similarly, C. parasitica, the causal agent of chestnut blight, was first detected in North America and Europe and not in its native range in Eastern Asia [55], as it happened for Hymenoscyphus fraxineus (synonym: $H$. pseudoalbidus), the ascomycete responsible for the epidemic of ash dieback in Europe [67].

Besides confirming the South African origin of P. multivora, our analyses of a large collection of isolates from six geographic populations suggest a complex spread of this species throughout the world with possible multiple introductions to specific continents (Fig. 5). In particular, some genotypes were directly introduced from South Africa to Europe in addition to those introduced from
Australia. The resulted genealogy indicates paraphyletic groups of Australian and South African genotypes cluster together, suggesting possible multiple introductions of $P$. multivora to Australia from South Africa. Both coalescent analyses, $\mathrm{ABC}$ and MASCOT, are in accordance that the North American population originated from Australia. While genotypes from the Canary Islands have a common ancestor with European isolates, they altogether might have Australian descent. Although there is no confirmation found in the phylogenetic coalescent analysis, that some P. multivora genotypes might had been introduced directly from South Africa to the Canary Islands, as suggested by the $\mathrm{ABC}$ analysis. Thus, the European population was most likely a secondary bridgehead for the invasion of the Canary Islands.

\section{Conclusions}

To summarize, our genetic analysis of the global population revealed the invasive history of Phytophthora multivora, emerging plant pathogen, most likely started in South Africa, followed by its introduction to Australia, and then spread worldwide from there. The conclusions were made based on a large collection of isolates from six populations (South Africa, Australia, Canary Islands, Europe, New Zealand, and North America) from geographic regions where $P$. multivora is currently known as widely distributed and abundant, or/and where it has a severe phytopathological impact. In future, new

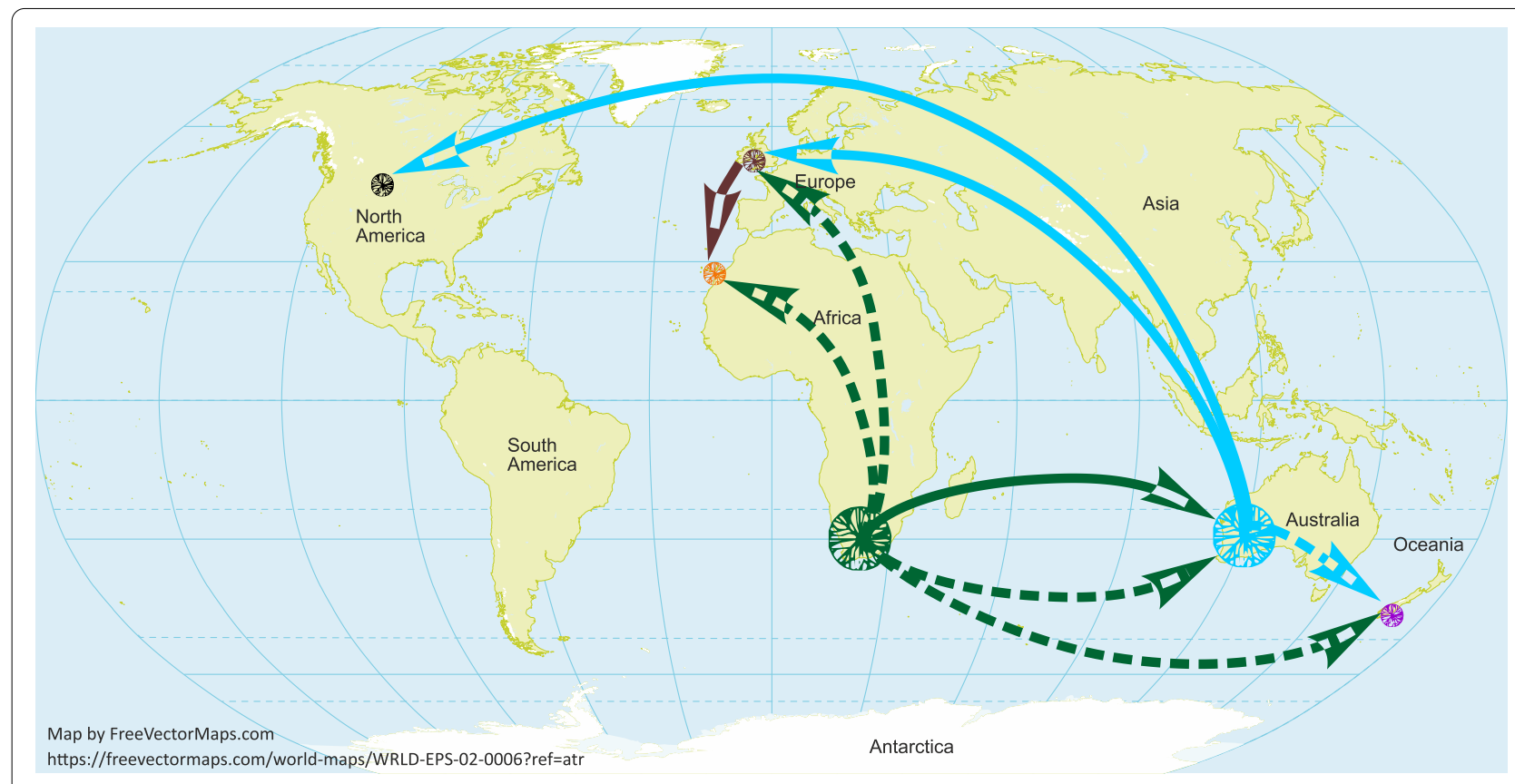

Fig. 5 Inferred global invasion history of the plant pathogen Phytophthora multivora. Solid lines indicate path confirmed by both ABC and MASCOT analysis; dashed lines show pathways inferred in one of the performed analyses 
P. multivora populations might be discovered and our results will have to be updated.

\section{Methods \\ Phytophthora multivora isolates}

We obtained 335 isolates of $P$. multivora from six distinct geographic locations: North America, Europe, South Africa, Australia, the Canary Islands, and New Zealand (Table S1).

\section{Single sequences repeat (SSR) genotyping}

Genomic DNA was extracted from the selected pure cultures of P. multivora using the DNeasy Plant Mini kit (Qiagen, Hilden, Germany) according to the manufacturer's protocol. All isolates were then genotyped at 10 microsatellite loci (PmMS02, PmMS04, PmMS06, PmMS07, PmMS08, PmMS10, PmMS12, PmMS14, PmMS18, and PmMS24) that were previously developed by [68]. All loci were PCR amplified using the following program: initial denaturation at $95^{\circ} \mathrm{C}$ for $5 \mathrm{~min}$; followed by $27 \mathrm{cycles}$ of $95^{\circ} \mathrm{C}$ for $30 \mathrm{~s}, 59^{\circ} \mathrm{C}$ for $90 \mathrm{~s}$, and $72^{\circ} \mathrm{C}$ for $30 \mathrm{~s}$; and a final extension of $60^{\circ} \mathrm{C}$ for $30 \mathrm{~min}$. The 10 microsatellite loci were amplified in three multiplex PCR reactions targeting each three to four loci (reaction 1: PmMS02, PmMS04, PmMS06, and PmMS07; reaction 2: PmMS08, PmMS10, and PmMS12; reaction 3: PmMS14, PmMS18, and PmMS24). All reactions were performed in $10 \mu \mathrm{L}$ volumes containing final concentrations of $1 x$ Type-it Multiplex PCR Master Mix (Qiagen) and $0.2 \mu \mathrm{M}$ of each primer and $1 \mu \mathrm{L}$ DNA. Forward primers were labeled at the $5^{\prime}$-end with a fluorescent dye (FAM: PmMS02-F, PmMS06-F, and PmMS12-f; PET: PmMS04-F, PmMS18-F, and PmMS24-F; NED: PmMS07-F, PmMS10-F, and PmMS14-F; VIC: PmMS08F), and amplicons were run on an ABI 3130 Genetic Analyzer using GeneScan 500 LIZ (Applied Biosystems, Carlsbad, CA, USA) as an internal size standard. Allele sizes were scored with GeneMapper Software 5 (Applied Biosystems).

\section{Amplification of mitochondrial and nuclear loci}

Six gene regions, 3 nuclear and 3 mitochondrial, were sequenced for 94 isolates of $P$. multivora (Table S1); 22 from South Africa, 30 from Western Australia, 3 from eastern Australia, 7 from the Canary Islands, 12 from Europe, 12 from New Zealand and 8 from the United States.

Genomic DNA was extracted from isolates as described previously [69]. For products to be cloned, GoTaq Hot Start Polymerase (Promega, Madison, USA) and buffer were used. Six gene regions were amplified; the mitochondrial intergenic spacer (coxIGS) between cytochrome oxidase 2 and cytochrome oxidase 1 [70], and the partial coding sequence for the cytochrome oxidase 1 (coxI) [70], NADH dehydrogenase subunit 1 (NADHI) [71], Enolase (ENOLASE) [72], Heat shock protein 90 (HSP90) [72], and the anti-silencing factor (ASF)-like gene (ASF) [70]. The reaction mixtures and cycling conditions for the amplification were as described previously in the original publications, except that $2 \mu \mathrm{L}$ of 1:10 diluted genomic DNA was used as a template. Products were cloned if additivity was observed in the initial sequence. These amplicons were cloned into a bacterial plasmid vector, pGEM ${ }^{\circledR}-\mathrm{T}$ Easy Vector System, as described previously [47], and 6-10 colonies were sequenced for each. The clean-up of amplicons using Sephadex and sequencing as described previously [73]. All sequences derived in this study are available from Data Dryad (https://datadryad.org).

\section{Data analysis}

We considered samples collected from each of the six geographically distinct locations as a single population of P. multivora. We used 10 SSR loci to study current population genetic diversity, structure, and demographic history of the global spread of P. multivora with Approximate Bayesian Computation (ABC). The SSR is generally considered neutral genetic markers [74] and therefore appropriate for stated research questions. Furthermore, we reconstructed the evolution of the P. multivora global population with Bayesian coalescent analysis using sequences of the three nuclear and three mitochondrial loci. In order to remove a putative clonal effect on the genetic structure, only one representative of each multilocus genotype (MLG) per population was considered.

\section{Genetic diversity}

Summary statistics on MLG, diversity indexes [75] and expected heterozygosity [76] were determined using the R-package poppr v 2.9.0 [77]. Allelic richness (Ar) per SSR locus and observed heterozygosity were estimated using the package Hierfstat v 0.5-7 [78]. The deviation from Hardy-Weinberg equilibrium [HWE, 79] was estimated using Arlequin 3.5.2.1 [79]. Pairwise linkage disequilibrium between loci was tested with the loglikelihood ratio using a Markov chain algorithm (default parameters), as implemented in the web version of Genepop 4.2 [80]. The statistical significance of LD was inferred using 1000 permutations and a sequential Bonferroni correction with $\alpha=0.05$. Genetic differentiation among populations was assessed by calculating pairwise $F_{\mathrm{ST}}$-values [81] and corresponding $P$-values $(\alpha=0.05)$ with Arlequin 3.5.2.1. Multilocus linkage disequilibrium was evaluated based on the $P$-values from one-sided permutation tests with the R-package poppr $\mathrm{v} 2.9 .0$ for the indices of association $\mathrm{I}_{\mathrm{A}}$ and $\mathrm{rD}$ (Agapow \& Burt 2001). 


\section{Population structure}

Genetic kinship of the P. multivora isolates recovered from different continents was examined using a multivariate clustering method, i.e. discriminant analysis of principle components (DAPC), implemented in the $\mathrm{R}$-package adegenet [82]. First, multilocus genetic data were transformed into principal components (PCs), and the optimal number of PCs was determined with crossvalidation [82]. Then $P$. multivora isolates with correspondent PCs were plotted along with the first two discriminant functions.

The genetic structure of the P. multivora global population with six assigned populations corresponding to the isolate's geographic origin (i.e. North America, Europe, South Africa, Australia, the Canary Islands, and New Zealand) was studied with the Bayesian model-based cluster analysis, as implemented in STRUCTURE v 2.3.4. The isolates were probabilistically assigned to genetic clusters using allele frequencies at each SSR locus. We used sampling locations of the populations as prior geographic information (LOCPRIOR $=1$ option) and the admixture ancestral model with correlated allele frequencies. Analyses were run with 200,000 burn-in iterations, followed by the same number of iterations for Markov chain Monte Carlo (MCMC) in 10 independent runs for each number of clusters (K) from 1 to 20 . The most likely $\mathrm{K}$ was determined, as suggested in [83], by (1) considering the maximal mean and small standard deviation of the posterior probability of K among runs [84], (2) applying $\Delta \mathrm{K}$ methods [85], using Structure Harvester [86], and (3) analyzing the alterations of individual assignment probabilities with increasing $\mathrm{K}$ (i.e. whether additional clusters were represented with a high probability by at least one specimen or whether probabilities rather were portioned among several individuals). Average assignment probabilities of specimens to the genetic clusters were computed with Clumpp 1.1.2 [87] using the greedy algorithm for $K \geq 10$ and visualized using $R$ graphic functions.

\section{History of spread}

The demographic history of the $P$. multivora spread among continents and the Canary Islands and New Zealand were investigated using a coalescent approximate Bayesian computation approach implemented in DIYABC v.2.1.0 [88]. The demographic scenario that best explained the observed genetic diversity in populations was inferred from two analysis steps (for details and prior population parameters, see Supplementary information). First, the six scenarios of the global origin of P. multivora were tested using the three most genetically diverse, and thus most likely oldest populations (see Results); populations from South Africa, Australia, and New Zealand.
Then, a range of sequential runs of determining the most probable alternative scenario was performed by adding one of the remaining less diverse populations; European, North American, and the Canary Islands' population (data not shown). Finally, considering population genetics results and assessments of intermediate evaluations of the alternative scenario for three minor populations, six most likely scenarios of the global distribution of $P$. multivora were hypothesized and tested. ABC analysis was conducted following [89], and included the following steps: 1) assume realistic competing scenarios considering structure, $\mathrm{F}_{\mathrm{ST}}$ ratio between sampled populations, and field observations; 2) simulate $1 \times 10^{6}$ pseudoobserved datasets (PODs) for each scenario and compute correspondent summary statistics; 3) evaluate posterior probabilities of each scenario on 1000 PODs with the closest summary statistic to the observed dataset and identify the best scenario in 95\% confidence interval; 4) assess the confidence level of the chosen scenario as the proportion of times this scenario was falsely rejected (type-I error) or accepted (type-II error); 5) evaluate the goodness-of-fit of the selected scenario to the data.

\section{Phylogeography}

In order to study the phylogeographic evolution of the $P$. multivora global population, we used sequences of three mitochondrial loci and three nuclear loci for each specimen of the studied geographic locations. The alignments of each molecular locus were done using the ClustalW method, then the substitution model that best fitted to the locus data based on the lowest BIC scores (Bayesian Information Criterion) was selected using MEGA7 software [90]. For each gene, only haplotypes were used to determine nucleotide and sequence diversity estimates as implemented in DNASP v. 6 [91].

Bayesian inferences about the evolution of the P. multivora global population were conducted by sampling trees with BEAST v2.6.2 package $[92,93]$. MCMC runs with $2 \times 10^{7}$ iterations were carried out. The effective sample size estimates were assessed in Tracer v1.7.1 [94]. The substitution model that best fit according to the lowest BIC was set for each locus. A strict molecular clock model was used. We estimated genealogical tree and time of coalescent events for six populations (i.e. North America, Europe, South Africa, Australia, the Canary Islands, and New Zealand) of $60 \mathrm{P}$. multivora specimens in total, using their mitochondrial multilocus data, specifically COI (concatenated coxI and coxIGS) and NADH1, following the statistical methodology implemented in StarBeast $[95,96]$. In order to compute time of coalescent events, we used a substitution rate of $2.4 \times 10^{-6}$ per site and per year, which was previously estimated for mitochondrial genomes of 
P. infestans [40]. Given the lack of recombination and relatively conservative evolution of the mitochondrial genome [41], we assumed this substitution rate to be applicable within the genus Phytophthora. We defined ancestral geographic location states following Marginal Approximation of the Structured Coalescent method [97, 98]. Specifically, we reconstructed the MASCOT tree for 60 specimens of $P$. multivora (Supplementary Table S1) from six geographically distant locations, using multilocus sequence data with nuclear genes (i.e. ASF, ENOLASE, and HSP90) and the three mitochondrial genes mentioned above. The mutation rate was set as a constant 1.0 and the estimation of branch lengths was calculated in substitutions per site. The summarizing trees for the phylogeographic origin of the P. multivora populations were executed using the location of origin as discrete states. The substitution rate and the substitution model that best fit according to the lowest BIC were set for each locus. The default priors for the StarBeast and the MASCOT trees with Log Normal options and exponential population models were generated using Beauti v2.6.6 [92, 93].. Maximum clade credibility consensus trees with mean node heights and 0.5 posterior probability limit were generated using TreeAnnotator v2.6.3 [92] and then visualized using FigTree v1.4.4.

\section{Abbreviations}

DAPC: Discriminant analysis of principal components; MASCOT: Marginal approximation of the structured coalescent analysis; MLG: Multilocus genotypes; PP: Posterior probability; SSR: Single sequences repeats.

\section{Supplementary Information}

The online version contains supplementary material available at https://doi. org/10.1186/s12864-022-08363-5.

\section{Additional file 1.}

\section{Acknowledgments}

We are grateful to Ana Perez Sierra (Spain), Eunsung Oh (South Africa), Nari Williams (New Zealand), and Nik Grünwald (USA) for providing isolates and valuable advice, Esther Jung for genotyping the isolates, and Diane White for laboratory support.

\section{Authors' contributions}

Conceived and designed the study: TIB, SP. Performed molecular analyses: CNS, AR. Analyzed the data: AR, CNS, TT. Statistical analysis: TT. Initial draft: TT. Writing, reviewing, and editing: TT, CNS, AR, TIB, SP. All authors read and approved the final manuscript.

\section{Funding}

No funding was obtained for this study.

\section{Availability of data and materials}

The datasets analysed during the current study are available in the Data Dryad repository by next links:

https://doi.org/10.5061/dryad.gxd2547nr

\section{Declarations}

Ethics approval and consent to participate

Not applicable.

\section{Consent for publication}

Not applicable.

\section{Competing interests}

The authors declare that they have no competing interests.

\section{Author details}

${ }^{1}$ Diversity and Evolution, Department Ecology and Evolution, GoetheUniversity Frankfurt am Main, Institute of Ecology, Max-von-Laue Str. 13, DE-60438 Frankfurt am Main, Germany. ${ }^{2}$ Senckenberg Biodiversity and Climate Research Centre SBiK-F, Georg-Voigt Str. 14-16, DE-60325 Frankfurt am Main, Germany. ${ }^{3}$ Swiss Federal Research Institute WSL, Zürcherstrasse 111, $\mathrm{CH}-8903$ Birmensdorf, Switzerland. ${ }^{4}$ Department of Diagnostic Genomics, PathWest Laboratory Medicine Western Australia, Nedlands, Western Australia, Australia. ${ }^{5}$ Phytophthora Science and Management, Harry Butler Institute, Murdoch, Perth, Australia. ${ }^{6}$ Forestry and Agriculture Biotechnology Institute, University of Pretoria, Pretoria 0002, South Africa.

Received: 30 August 2021 Accepted: 3 February 2022

Published online: 22 February 2022

\section{References}

1. Santini A, Ghelardini L, De Pace C, Desprez-Loustau ML, Capretti P, Chandelier A, et al. Biogeographical patterns and determinants of invasion by forest pathogens in Europe. New Phytol. 2013;197(1):238-50.

2. Chapman D, Purse BV, Roy HE, Bullock JM. Global trade networks determine the distribution of invasive non-native species. Glob Ecol Biogeogr. 2017:26(8):907-17.

3. Bradley BA, Blumenthal DM, Early R, Grosholz ED, Lawler JJ, Miller LP, et al. Global change, global trade, and the next wave of plant invasions. Front Ecol Environ. 2012;10(1):20-8.

4. Scott P, Bader MKF, Burgess T, Hardy G, Williams N. Global biogeography and invasion risk of the plant pathogen genus Phytophthora. Environ Sci Pol. 2019;101:175-82.

5. Crous PW, Rossman AY, Aime C, Allen C, Burgess T, Groenewald JZ, et al. Names of phytopathogenic fungi: a practical guide. Phytopathology. 2021;0(ja):null.

6. Roderick GK, Navajas M. Genes in new environments: genetics and evolution in biological control. Nat Rev Genet. 2003;4(11):889-99.

7. McDonald BA, Linde C. The population genetics of plant pathogens and breeding strategies for durable resistance. Euphytica. 2002;124(2):163-80

8. Dandy N, Marzano M, Porth EF, Urquhart J, Potter C. Who has a stake in ash dieback? A conceptual framework for the identification and categorisation of tree health stakeholders; 2017.

9. Erwin DC, Ribeiro OK. Phytophthora diseases worldwide. St Paul, Minnesota: American Phytopathological Society (APS Press); 1996.

10. Hansen EM, Reeser PW, Sutton W. Phytophthora beyond agriculture. Annu Rev Phytopathol. 2012;50(1):359-78.

11. Jung T, Burgess T. Re-evaluation of Phytophthora citricola isolates from multiple woody hosts in Europe and North America reveals a new species, Phytophthora plurivora sp. nov. Persoonia. 2009;22(1):95-110.

12. Scott PM, Burgess TI, Barber PA, Shearer BL, Stukely MJC, Hardy GESJ, et al. Phytophthora multivora sp. nov., a new species recovered from declining Eucalyptus, Banksia, Agonis and other plant species in Western Australia. Persoonia. 2009;22:1-13.

13. Hong C, Gallegly ME, Richardson PA, Kong P. Phytophthora pini Leonian resurrected to distinct species status. Mycologia. 2011;103(2):351-60.

14. Bezuidenhout CM, Denman S, Kirk SA, Botha WJ, Mostert L, McLeod A. Phytophthora taxa associated with cultivated Agathosma, with emphasis on the P. citricola complex and P. capensis sp. nov. Persoonia. 2010;25:32-49. 
15. Henricot B, Pérez Sierra A, Jung T. Phytophthora pachypleura sp. nov., a new species causing root rot of Aucuba japonica and other ornamentals in the United Kingdom. Plant Pathol. 2014;63(5):1095-109.

16. Ginetti B, Moricca S, Squires JN, Cooke DEL, Ragazzi A, Jung T. Phytophthora acerina sp. nov., a new species causing bleeding cankers and dieback of Acer pseudoplatanus trees in planted forests in northern Italy. Plant Pathol. 2014;63(4):858-76.

17. Brazee NJ, Yang X, Hong CX. Phytophthora caryae sp. nov., a new species recovered from streams and rivers in the eastern United States. Plant Pathol. 2017;66(5):805-17.

18. Bose T, Hulbert JM, Burgess TI, Paap T, Roets F, Wingfield MJ. Two novel Phytophthora species from the southern tip of Africa. Mycol Prog. 2021;20(6):755-67.

19. Jung T, Orlikowski L, Henricot B, Abad-Campos P, Aday AG, Aguín Casal $\mathrm{O}$, et al. Widespread Phytophthora infestations in European nurseries put forest, semi-natural and horticultural ecosystems at high risk of Phytophthora diseases. Forest Pathol. 2016;46(2):134-63.

20. Jung T, Pérez-Sierra A, Durán A, Horta MJ, Balci Y, Scanu B. Canker and decline diseases caused by soil-and airborne Phytophthora species in forests and woodlands. Persoonia. 2018;40:182-220.

21. Molnar C, Nikolaeva E, Kim S, Olson T, Bily D, Kim J-E, et al. Phytophthora diversity in Pennsylvania nurseries and greenhouses inferred from clinical samples collected over four decades. Microorganisms. 2020;8(7):1056.

22. Prospero S, Vercauteren A, Heungens K, Belbahri L, Rigling D. Phytophthora diversity and the population structure of Phytophthora ramorum in Swiss ornamental nurseries. Plant Pathol. 2013;62(5):1063-71.

23. Schoebel CN, Stewart J, Gruenwald NJ, Rigling D, Prospero S. Population history and pathways of spread of the plant pathogen Phytophthora plurivora. PLoS One. 2014;9(1):e85368.

24. Migliorini D, Khdiar MY, Padrón CR, Vivas M, Barber PA, Hardy GESJ, et al. Extending the host range of Phytophthora multivora, a pathogen of woody plants in horticulture, nurseries, urban environments and natural ecosystems. Urban For Urban Green. 2019;46:126460.

25. Oh E, Gryzenhout M, Wingfield BD, Wingfield MJ, Burgess TI. Surveys of soil and water reveal a goldmine of Phytophthora diversity in south African natural ecosystems. IMA Fungus. 2013;4(1):123-31.

26. Puno VI, Laurence MH, Guest DI, Liew ECY. Detection of Phytophthora multivora in the Wollemi pine site and pathogenicity to Wollemia nobilis. Australas Plant Path. 2015;44(2):205-15.

27. Aldaoud R, Salib S, Dinh S, de Alwis S, Holmes R, Edwards J. Host records for Phytophthora multivora associated with dieback in Victoria, Australia. Aust Plant Dis Notes. 2016;11(1):4.

28. Rodriguez-Padron C, Siverio F, Perez-Sierra A, Rodriguez A. Isolation and pathogenicity of Phytophthora species and Phytopythium vexans recovered from avocado orchards in the Canary Islands, including Phytophthora niederhauserii as a new pathogen of avocado. Phytopathol Mediterr. 2018:57(1):89-106.

29. Puglisi I, De Patrizio A, Schena L, Jung T, Evoli M, Pane A, et al. Two previously unknown Phytophthora species associated with brown rot of Pomelo (Citrus grandis) fruits in Vietnam. PLoS One. 2017;12(2):e0172085.

30. Zea-Bonilla T, Martín-Sánchez PM, Hermoso JM, Carmona MP, Segundo E, Pérez-Jimenéz RM. First report of Phytophthora citricola on Mangifera indica in Spain. Plant Pathol. 2007;56(2):356.

31. Garbelotto MM, Frankel S, Scanu B. Soil- and waterborne Phytophthora species linked to recent outbreaks in northern California restoration sites. Calif Agric. 2018;72(4):208-16.

32. Rooney-Latham S, Blomquist CL, Kosta KL, Gou YY, Woods PW. Phytophthora species are common on nursery stock grown for restoration and Revegetation purposes in California. Plant Dis. 2019;103(3):448-55.

33. Bienapfl JC, Balci Y. Movement of Phytophthora spp. in Maryland's Nursery Trade. Plant Dis. 2014;98(1):134-44

34. Rahman MZ, Uematsu S, Suga H, Kageyama K. Diversity of Phytophthora species newly reported from Japanese horticultural production. Mycoscience. 2015;56(4):443-59.

35. Rahman MZ, Uematsu S, Kimishima E, Kanto T, Kusunoki M, Motohashi K, et al. Two plant pathogenic species of Phytophthora associated with stem blight of Easter lily and crown rot of lettuce in Japan. Mycoscience. 2015;56(4):419-33.

36. Wang J, Coffey MD, De Maio N, Goss EM. Repeated global migrations on different plant hosts by the tropical pathogen Phytophthora palmivora. BioRxiv. 2020.05.13.093211. https://doi.org/10.1101/2020.05.13.093211.
37. Mallez S, Castagnone C, Espada M, Vieira P, Eisenback JD, Harrell M, et al. Worldwide invasion routes of the pinewood nematode: what can we infer from population genetics analyses? Biol Invasions. 2015;17(4):1199-213.

38. Socorro Serrano M, Osmundson T, Almaraz-Sánchez A, Croucher PJP, Swiecki T, Alvarado-Rosales D, et al. A microsatellite analysis used to identify global pathways of movement of Phytophthora cinnamomi and the likely sources of Wildland infestations in California and Mexico. Phytopathology. 2019;109(9):1577-93.

39. Watterson GA. On the number of segregating sites in genetical models without recombination. Theor Popul Biol. 1975;7(2):256-76.

40. Yoshida K, Schuenemann VJ, Cano LM, Pais M, Mishra B, Sharma R, et al. The rise and fall of the Phytophthora infestans lineage that triggered the Irish potato famine. Elife. 2013;2:e00731.

41. Stewart S, Robertson AE, Wickramasinghe D, Draper MA, Michel A, Dorrance AE. Population structure among and within lowa, Missouri, Ohio, and South Dakota populations of Phytophthora sojae. Plant Dis. 2016:100(2):367-79.

42. De Meeûs T, McCoy KD, Prugnolle F, Chevillon C, Durand P, HurtrezBousses $\mathrm{S}$, et al. Population genetics and molecular epidemiology or how to "débusquer la bête". Infect Genet Evol. 2007;7(2):308-32.

43. Goodwin SB. The population genetics of Phytophthora. Phytopathology. 1997;87(4):462-73

44. Grünwald NJ, Everhart SE, Knaus BJ, Kamvar ZN. Best practices for population genetic analyses. Phytopathology. 2017;107(9):1000-10.

45. Bassani I, Larousse M, Tran QD, Attard A, Galiana E. Phytophthora zoospores: from perception of environmental signals to inoculum formation on the host-root surface. Comput Struct Biotechnol J. 2020;18:3766-73.

46. Judelson HS, Blanco FA. The spores of Phytophthora: weapons of the plant destroyer. Nat Rev Microbiol. 2005;3:47.

47. Nagel JH, Gryzenhout M, Slippers B, Wingfield MJ, Hardy GES, Stukely MJC, et al. Characterization of Phytophthora hybrids from ITS clade 6 associated with riparian ecosystems in South Africa and Australia. Fungal Biol. 2013;117:329-47.

48. Hulbert JM, Paap T, Burgess TI, Roets F, Wingfield MJ. Botanical gardens provide valuable baseline Phytophthora diversity data. Urban For Urban Green. 2019;46:126461

49. Horner I, Hough E. Pathogenicity of four Phytophthora species on kauri in vitro and glasshouse trials. New Zealand Plant Protection. 2014;67:54-9.

50. Waipara N, Hill S, Hill L, Hough E, Horner I. Surveillance methods to determine tree health distribution of kauri dieback disease and associated pathogens. N Z Plant Prot. 2013;66:235-41.

51. Scott P, Williams N. Phytophthora diseases in New Zealand forests. NZ J Forestry. 2014;59(2):15.

52. King CM. How genetics, history and geography limit potential explanations of invasions by house mice Mus musculus in New Zealand. Bio Invasions. 2016;18(6):1533-50.

53. Brasier CM. The biosecurity threat to the UK and global environment from international trade in plants. Plant Pathol. 2008;57(5):792-808.

54. Grünwald NJ, Garbelotto M, Goss EM, Heungens K, Prospero S. Emergence of the sudden oak death pathogen Phytophthora ramorum. Trends Microbiol. 2012;20(3):131-8.

55. Rigling D, Prospero S. Cryphonectria parasitica, the causal agent of chestnut blight: invasion history, population biology and disease control. Mol Plant Pathol. 2018;19(1):7-20.

56. Santini A, Liebhold A, Migliorini D, Woodward S. Tracing the role of human civilization in the globalization of plant pathogens. ISME J. 2018;12(3):647-52.

57. Haack RA, Hérard F, Sun J, Turgeon JJ. Managing invasive populations of Asian longhorned beetle and citrus longhorned beetle: a worldwide perspective. Annu Rev Entomol. 2010;55(1):521.

58. Franić I, Prospero S, Hartmann M, Allan E, Auger-Rozenberg M-A, Grünwald NJ, et al. Are traded forest tree seeds a potential source of nonnative pests? Ecol Appl. 2019;29(7):e01971.

59. Burgess T, Wingfield MJ: Quarantine is important in restricting the spread of exotic seed-borne tree pathogens in the southern hemisphere. Int for Rev. 2002;4(1):56-65.

60. Wingfield MJ, Brockerhoff EG, Wingfield BD, Slippers B. Planted forest health: the need for a global strategy. Science. 2015;349(6250):832-6. 
61. Tsykun T, Javal M, Hölling D, Roux G, Prospero S. Fine-scale invasion genetics of the quarantine pest, Anoplophora glabripennis, reconstructed in single outbreaks. Sci Rep. 2019;9(1):19436.

62. Javal M, Lombaert E, Tsykun T, Courtin C, Kerdelhué C, Prospero S, et al. Deciphering the worldwide invasion of the Asian long-horned beetle: a recurrent invasion process from the native area together with a bridgehead effect. Mol Ecol. 2019;28(5):951-67.

63. Lombaert E, Guillemaud T, Cornuet JM, Malausa T, Facon B, Estoup A: Bridgehead effect in the worldwide invasion of the biocontrol harlequin ladybird. PLoS One 2010, 5(3):e9743.

64. Fontaine MC, Labbé F, Dussert Y, Delière L, Richart-Cervera S, Giraud T, et al. Europe as a bridgehead in the worldwide invasion history of grapevine downy mildew, Plasmopara viticola. Curr Biol. 2021;31(10):21552166.e2154.

65. Leduc A, Traoré YN, Boyer K, Magne M, Grygiel P, Juhasz C, et al. Bridgehead invasion of a monomorphic plant pathogenic bacterium: Xanthomonas citri pv. Citri, an emerging citrus pathogen in Mali and Burkina Faso. Environ Microbiol. 2015;17(11):4429-42.

66. Mack RN, Simberloff D, Mark Lonsdale W, Evans H, Clout M, Bazzaz FA. Biotic invasions: causes, epidemiology, global consequences, and control. Ecol Appl. 2000;10(3):689-710.

67. Gross A, Hosoya T, Queloz V. Population structure of the invasive forest pathogen Hymenoscyphus pseudoalbidus. Mol Ecol. 2014;23(12):2943-60.

68. Schoebel CN, Jung E, Prospero S. Development of new polymorphic microsatellite markers for three closely related plant-pathogenic Phytophthora species using 454-pyrosequencing and their potential applications. Phytopathology. 2013;103(10):1020-7.

69. Andjic V, Cortinas M-N, Hardy GES, Wingfield MJ, Burgess TI. Multiple gene genealogies reveal important relationships between species of Phaeophleospora infecting Eucalyptus leaves. FEMS Microbiol Lett. 2007:268:22-33.

70. Martin FN, Tooley PW. Phylogenetic relationships among Phytophthora species inferred from sequence analysis of mitochondrially encoded cytochrome oxidase I and II genes. Mycologia. 2003;95(2):269-84.

71. Kroon L, Bakker FT, van den Bosch GBM, Bonants PJM, Flier WG. Phylogenetic analysis of Phytophthora species based on mitochondrial and nuclear DNA sequences. Fungal Genet Biol. 2004;41(8):766-82.

72. Blair JE, Coffey MD, Park SY, Geiser DM, Kang S. A multi-locus phylogeny for Phytophthora utilizing markers derived from complete genome sequences. Fungal Genet Biol. 2008;45(3):266-77.

73. Sakalidis ML, Hardy GES, Burgess TI. Endophytes and potential pathogens of the baobab species Adansonia gregorii; a focus on the Botryosphaeriaceae. Fungal Ecol. 2011;4:1-14.

74. Tsykun T, Rellstab C, Dutech C, Sipos G, Prospero S. Comparative assessment of SSR and SNP markers for inferring the population genetic structure of the common fungus Armillaria cepistipes. Heredity. 2017;119(5):371-80

75. Grünwald NJ, Goodwin SB, Milgroom MG, Fry WE. Analysis of genotypic diversity data for populations of microorganisms. Phytopathology. 2003;93(6):738-46.

76. Nei M. Estimation of average heterozygosity and genetic distance from a small number of individuals. Genetics. 1978;89(3):583-90.

77. Kamvar ZN, Brooks JC, Grünwald NJ: Novel R tools for analysis of genomewide population genetic data with emphasis on clonality. Front Genet. 2015;6:208.

78. Goudet J. Hierfstat, a package for R to compute and test hierarchical F-statistics. Mol Ecol Notes. 2005;5(1):184-6.

79. Excoffier L, Hofer T, Foll M. Detecting loci under selection in a hierarchically structured population. Heredity. 2009;103(4):285-98.

80. Rousset F. genepop'007: a complete re-implementation of the genepop software for windows and Linux. Mol Ecol Resour. 2008;8(1):103-6.

81. Weir BS, Cockerham CC: Estimating F-Statistics for the Analysis of Population Structure. Evolution. 1984;38(6):1358-70.

82. Jombart T, Devillard S, Balloux F. Discriminant analysis of principal components: a new method for the analysis of genetically structured populations. BMC Genet. 2010;11(1):94.

83. Janes JK, Miller JM, Dupuis JR, Malenfant RM, Gorrell JC, Cullingham Cl, et al. The $K=2$ conundrum. Mol Ecol. 2017;26(14):3594-602.

84. Pritchard JK, Stephens M, Donnelly P. Inference of population structure using multilocus genotype data. Genetics. 2000;155(2):945-59.
85. Evanno G, Regnaut S, Goudet J. Detecting the number of clusters of individuals using the software STRUCTURE: a simulation study. Mol ECol. 2005;14(8):2611-20

86. Earl DA, vonHoldt BM. STRUCTURE HARVESTER: a website and program for visualizing STRUCTURE output and implementing the Evanno method. Conserv Genet Resour. 2011;4(2):359-61.

87. Jakobsson M, Rosenberg NA. CLUMPP: a cluster matching and permutation program for dealing with label switching and multimodality in analysis of population structure. Bioinformatics. 2007;23(14):1801-6.

88. Cornuet J-M, Pudlo P, Veyssier J, Dehne-Garcia A, Gautier M, Leblois R, et al. DIYABC v2.0: a software to make approximate Bayesian computation inferences about population history using single nucleotide polymorphism, DNA sequence and microsatellite data. Bioinformatics. 2014;30(8):1187-9.

89. Cornuet J-M, Ravigné V, Estoup A. Inference on population history and model checking using DNA sequence and microsatellite data with the software DIYABC (v1.0). BMC Bioinformatics. 2010;11(1):401.

90. Kumar S, Stecher G, Tamura K. MEGA7: molecular evolutionary genetics analysis version 7.0 for bigger datasets. Mol Biol Evol. 2016;33(7):1870-4

91. Rozas J, Ferrer-Mata A, Sánchez-DelBarrio JC, Guirao-Rico S, Librado P, Ramos-Onsins SE, et al. DnaSP 6: DNA sequence polymorphism analysis of large data sets. Mol Biol Evol. 2017;34(12):3299-302.

92. Bouckaert R, Vaughan TG, Barido-Sottani J, Duchêne S, Fourment M, Gavryushkina A, et al. BEAST 2.5: an advanced software platform for Bayesian evolutionary analysis. PLoS Comput Biol. 2019;15(4):e1006650.

93. Drummond, Bouckaert: Bayesian evolutionary analysis with BEAST / Alexei J. Drummond, Remco R. Bouckaert. In. 2015.

94. Rambaut A, Drummond AJ, Xie D, Baele G, Suchard MA. Posterior summarization in Bayesian Phylogenetics using tracer 1.7. Syst Biol. 2018;67(5):901-4.

95. Drummond AJ, Xie W, Heled J. Bayesian inference of species trees from multilocus data using* BEAST. Mol Biol Evol. 2012;29:1969-73.

96. Ogilvie HA, Bouckaert RR, Drummond AJ. StarBEAST2 brings faster species tree inference and accurate estimates of substitution rates. Mol Bio Evol. 2017;34(8):2101-14.

97. Müller NF, Rasmussen DA, Stadler T. The structured coalescent and its approximations. Mol Biol Evol. 2017;34(11):2970-81.

98. Müller NF, Rasmussen D, Stadler T. MASCOT: parameter and state inference under the marginal structured coalescent approximation. Bioinformatics. 2018;34(22):3843-8.

\section{Publisher's Note}

Springer Nature remains neutral with regard to jurisdictional claims in published maps and institutional affiliations.

Ready to submit your research? Choose BMC and benefit from:

- fast, convenient online submission

- thorough peer review by experienced researchers in your field

- rapid publication on acceptance

- support for research data, including large and complex data types

- gold Open Access which fosters wider collaboration and increased citations

- maximum visibility for your research: over $100 \mathrm{M}$ website views per year

At BMC, research is always in progress.

Learn more biomedcentral.com/submissions 